\title{
Bibliografía del prof. Mitja Skubic
}

1952

Artículos y contribuciones breves

Benedettu Croceju v spomin. - Ljubljanski dnevnik 2, št. 239, Ljubljana 1952, p. 3

1956

Artículos y contribuciones breves

Retoromanščina, četrti nacionalni jezik v Švici. - Tedenska tribuna TT 4, št. 12, Ljubljana 1956, p. 9

Osemindvajseta »Biennale«. - Slovenski poročevalec 17, št. 171, Ljubljana 1956, p. 6

\section{3}

\section{Artículos}

Le forme del preterito nel Goldoni. - Lingua nostra 24, Firenze 1963, pp. 42-44 Le passé simple et le passé composé dans la langue des troubadours. - Linguistica 5, Ljubljana 1963, pp. 61-70

Artículos y contribuciones breves

Profesor Stanko Škerlj sedemdesetletnik. - Delo 5, št.36, Ljubljana 1963, p. 5

1964

Artículos

Pretérito simple y compuesto en el español hablado. - Linguistica 6, Ljubljana 1964, pp. 87-90 


\section{5}

\section{Libros y monografías}

Corso d'italiano 1/Sušjan A. - Ljubljana: Zavod intenzivni tečaji tujih jezikov, $1965,168 \mathrm{pp}$.

Corso d'italiano 2/Sušjan A. - Ljubljana: Zavod intenzivni tečaji tujih jezikov, $1965,191 \mathrm{pp}$.

Corso d'italiano 3/Sušjan A. - Ljubljana: Zavod intenzivni tečaji tujih jezikov, $1965,175 \mathrm{pp}$.

\section{Tesis doctoral}

Prispevki k poznavanju zgodovine preterita v italijanščini. - Ljubljana, 1965, 470+VI f.

\section{Artículos}

Norma v sodobni italijanščini. - Jezik in slovstvo 10, št. 2/3, Ljubljana 1965, pp. $87-95$

Il pretérito nel toscano parlato. - Linguistica 7/1, Ljubljana 1965, pp. 85-90

\section{Artículos y contribuciones breves}

Zapiski iz Španije. - Naši razgledi 14, št. 22, Ljubljana 1965, pp. 455

Zapiski iz Španije. - Naši razgledi 14, št. 23, Ljubljana 1965, pp. 474-475

\section{6}

\section{Artículos}

Le forme del preterito nei Promessi sposi. - Filološki pregled 4, št.1-4, Beograd 1966, pp. 139-143

Il valore del piuccheperfetto nella lingua della stampa italiana contemporanea. - Linguistica 8/1, Ljubljana 1966/68, pp. 105-114

Correspondances lexicales dans la langue de la presse contemporaine. - Linguistica 8/2, Ljubljana 1966/68, pp. 187-211 
1967

\section{Artículos}

Le sorti del preterito nel Bembo e in altri Cinquecentisti. - Lingua nostra 28, Firenze 1967, pp. 19-22

\section{Artículos y contribuciones breves}

Anton Grad šestdesetletnik. - Delo 8, št. 51, Ljubljana 1967, p. 5

1968

\section{Contribuciones científicas}

Pretérito semplice e composto in Dante. - V: Zbornik o Danteu, Beograd: Prosveta, 1968 , pp. 71-76

Reseñas, evaluaciones, informes

Linguistica. - Delo 10, št. 321, Ljubljana 1968, p. 18

\section{9}

\section{Contribuciones científicas}

Pretérito simple y compuesto en los primeros textos castellanos. - V: Actas de XI Congreso internacional de lingüistica y filología románicas 4, Madrid: CSIC, 1969, pp. 1891-1900

\section{Artículos}

Correspondances lexicales dans la langue de la presse contemporaine II. Linguistica 9/1, Ljubljana 1969, pp. 53-109

Besedni romanizmi v slovenskem časopisnem jeziku. - Jezik in slovstvo 15, Ljubljana $1969 / 70$, pp. $45^{-54}$

\section{Artículos y contribuciones breves}

Linguistica. - Delo 11, št. 172, Ljubljana 1969, p. 5 


\section{Reseñas, evaluaciones, informes}

Iorgu Iordan. Lingüistica románica. Evolución - corrientes métodos, Madrid: ed. Alcalá 1967. - Linguistica 9/2, Ljubljana 1969, pp. 197-199

Roland Barthes. Il grado zero della scrittura, Lerici ed.: Milano 1967. - Linguistica 9/2, Ljubljana 1969, pp. 199-201

\section{0}

\section{Contribuciones científicas}

Il valore del piuccheperfetto nella prosa italiana contemporanea. - V: Actele celui de XII Congres International de Lingvistica şi Filologie Romanica 1, ed. Academiei republicii socialiste românia: Bucureşti, 1970, pp. 487-495

\section{Artículos}

Primer sintaktičnega kalka. Jezik in slovstvo 16, št. 3, Ljubljana 1970/71, pp. 68-70

Contributi alla storia del preterito nell'italiano. - Razprave. Razred za filološke in literarne vede pri SAZU 2, št. 7, Ljubljana 1970, pp. 345-400

Il congiuntivo nel Goldoni. - Linguistica 10, Ljubljana 1970, pp. 107-110

\section{1}

\section{Libros y monografías}

Jezikovni priročnik za napovedovalce/Orešnik J., Jakopin F.. - Ljubljana: Delavska univerza Boris Kidrič, 1971, 91 pp.

\section{Artículos}

Contributi alla sintassi del verbo nei dialetti veneti. - Linguistica 11, Ljubljana 1971, pp. 71-84

Soprannomi nella parlata veneta di Pirano. - Linguistica 11, Ljubljana 1971, pp. $85-92$

Contributi alla conoscenza delle sorti del preterito nell'area veneta. - Studi di grammatica italiana 1, Firenze 1971, pp. 117-177 
1972

\section{Artículos}

Il congiuntivo nei piú antichi testi non letterari veneziani. - Živa antika 22, Skopje 1972, pp. 195-202

Il congiuntivo nei primi testi letterari in volgare veneto. - Linguistica 12, Ljubljana 1972, pp. 229-257

Norma in sistem. - Jezik in slovstvo 18, št. 4, Ljubljana 1972/73, pp. 128-132

Sosledica časov v beneškem govoru Pirana. - Slavistična revija 20, št. 1, Ljubljana 1972, pp. 127-134

\section{Artículos y contribuciones breves}

Profesor Stanko Škerlj - osemdesetletnik. - Jezik in slovstvo 18, št. 4, Ljubljana $1972 / 73$, pp. $142-143$

\section{3}

\section{Artículos}

La lingua della cancelleria del comune di Pirano nel Cinquecento. - Linguistica 13, Ljubljana 1973, pp. 262-276

Le due forme del preterito nell'area siciliana. - Atti dell'Academia di Scienze Lettere e Arti di Palermo 4, št. 33/2, Palermo 1973/74, pp. 225-293

\section{Artículos y contribuciones breves}

Osemdeset let Stanka Škerlja. - Delo 15, št. 36, Ljubljana 1973, p. 6

Akademik Stanko Škerlj. Osemdesetletnica. - Naši razgledi 22, št. 5, Ljubljana 1973, p. 120

\section{4}

\section{Libros y monografías}

Curso de español 1. - Ljubljana: Zavod intenzivni tečaji tujih jezikov, 1974, 143 pp.

Curso de español 2. - Ljubljana: Zavod intenzivni tečaji tujih jezikov, 1974, 211 pp. 


\section{Contribuciones científicas}

Un testo contemporaneo non letterario: Isola d'Istria. - V: L'italiano oggi: lingua non letteraria e lingue speciali. - Trieste: Lint, 1974, pp. 383-391

\section{Artículos}

Il congiuntivo italiano delle opere letterarie contemporanee nelle traduzioni in sloveno. - Linguistica 14, Ljubljana 1974, pp. 77-94

\section{5}

\section{Artículos}

Una pagina della parlata veneta a Pirano: lungo come. - Italica Belgradensia 1, Beograd 1975, pp. 235-241

Le due forme del preterito nell'area siciliana II. - Atti dell'Academia di Scienze Lettere e Arti di Palermo 4, št. 34/2, Palermo 1975, pp. 353-427

Contribution à la syntaxe du verbe en catalan. - Linguistica 15, Ljubljana 1975, pp. $185-196$

\section{Artículos y contribuciones breves}

Akademik prof. dr. Stanko Škerlj. In memoriam. - Naši razgledi 24, št. 21, Ljubljana 1975, p. 561

\section{6}

\section{Contribuciones científicas}

La parlata veneta di Pirano tra italiano, friulano e sloveno. - V: Atti del XIV. Congresso internazionale di linguistica e filologia romanza 2, Napoli: Gaetano Macchiaroli, 1976, pp. 469-487

\section{Artículos y contribuciones breves}

Akad. Prof. dr. Stanko Škerlj. - Objave Univerze v Ljubljani, št. 3-4, Ljubljana 1974/75, pp. $134^{-137}$ 


\section{7}

\section{Libros y monografías}

Curso de español 1. Ponatis. - Ljubljana: Zavod intenzivni tečaji, 1977, 143 pp.

\section{Contribuciones científicas}

»Io ero da te e tu non c'eri«. - V: L'italiano oggi: lingua nazionale e varietà regionali. - Trieste: Lint, 1977, pp. 309-314

\section{Artículos}

Contribuţii la sintaxa formelor verbale în graiul venet din Istria. - Analele societății de limba română 8, Zrenjanin 1977, pp. 184-188

\section{Artículos y contribuciones breves}

Furlanščina. Pogovorni jezik v Trstu je bil še v 18. stoletju, kolikor je bil romanski, zanesljivo furlanski in ne beneški. - Naši razgledi 26, št. 11, Ljubljana 1977, pp. 284-285

Anton Grad - sedemdesetletnik. - Delo 19, št. 45, Ljubljana 1977, p. 8

\section{8}

\section{Artículos}

Sur les valeurs des temps du passé dans les langues romanes. - Linguistica 17, Ljubljana 1978, pp. 143-150

\section{Artículos y contribuciones breves}

Linguistica XVII. - Naši razgledi 27, št. 22, Ljubljana 1978, pp. 654

\section{Reseñas, evaluaciones, informes}

Giovan Battista Pellegrini. Studi di dialettologia e filologia veneta, Pacini ed.: Pisa 1977. - Linguistica 18, Ljubljana 1978, pp. 265-268 


\section{9}

\section{Contribuciones científicas}

Primerjava, začetna stopnja metafore. - Traditiones: acta instituti etnograpbiae slovenorum, št 5/6, 1976/1977, Ljubljana 1979, pp. 323-328

\section{Artículos}

Oracions subordinades amb infinitiu en el català antic. - Linguistica 19, Ljubljana 1979, pp. 243-255

Bilingvizem na slovenski obali. - Godišnjak Saveza društava za primenjenu lingvistiku Jugoslavije 3, Beograd 1979, pp. 101-105

\section{Reseñas, evaluaciones, informes}

Milivoj Minić. Uvod u nauku o jeziku. - Vestnik 13/2, Ljubljana 1979, pp. 77-81 Linguistica XVIII. - Naši razgledi 28, št. 15, Ljubljana 1979, p. 442

\section{0}

\section{Reseñas, evaluaciones, informes}

Anton Grad. Slovensko-španski slovar, Ljubljana 1979. - Vestnik 14/2, Ljubljana $1980, \mathrm{pp} \cdot 75^{-78}$

Dr. Anton Grad. Slovensko-španski slovar. - Naši razgledi 29, št. 15, Ljubljana 1980, p. 434

\section{1}

\section{Contribuciones científicas}

Fonti del lessico agrario nell'Istria Nord-occidentale: interferenze slavo-venete. - V: Atti del 12. Convegno per gli studi dialettali italiani, Pisa: Pacini ed., 1981, pp. 209-215

\section{Artículos}

Appunti sulle subordinate oggettive volitive in italiano. - Biblos 57, Coimbra 1981, pp. 224-228 
La langue des inscriptions latines en Slovénie. - Linguistica 21, Ljubljana 1981, pp. $277^{-298}$

Il congiuntivo italiano in chiave contrastiva. - Scuola nostra 12, Rijeka 1981, pp. $41-52$

Romanistika na ljubljanski Univerzi. - Antbropos 12, št. 4/6, Ljubljana 1981, pp. $336-340$

Reseñas, evaluaciones, informes

Linguistica XX. - Delo 23, št.183, Ljubljana 1981, p. 7

\section{2}

\section{Libros y monografías}

Uvod v romansko jezikoslovje. - Ljubljana: Filozofska fakulteta, 1982, 326 pp.

\section{Artículos}

Retoromanščina. Ob članku G.B. Pellegrinija: Alcune osservazioni sul retoromanzo. - Linguistica 22, Ljubljana 1982, pp. 56-64

\section{Artículos y contribuciones breves}

Mesto katalonščine v romanskem svetu. Povzetek iz predavanja ob ustanovitvi katedre za španščino na Filozofski fakulteti v Ljubljani. - Naši razgledi 31 , št. 11, Ljubljana 1982, p. 347

\section{Reseñas, evaluaciones, informes}

Emilio De Felice. Il nomi degli italiani. Informazioni onomastiche e linguistiche, socioculturali e religiose. Rilevamenti quantitativi dei nomi personali dagli elenchi telefonici, Marsilio Ed.: Venezia 1982. - Linguistica 22, Ljubljana 1982, pp. 299-312

Pavao Tekavčić, Uvod u lingvistiku. Zagreb 1979. - Vestnik 16, št. 2, Ljubljana 1982 , pp. $48-51$ 


\section{3}

\section{Contribuciones científicas}

Die italienischsprachige Bevölkerung in Istrien zwischen Bilinguismus und Diglossie. - V: Das Patriarchat Aquileia - Schnittpunkt der kulturen (Schriftenreihe des Regensburger Osteuropainstituts, Band 10), Lassleben: Regensburg, 1983, pp. 57-68

Appunti sui nomi di famiglia quattrocenteschi a Pirano. - V: Scritti linguistici in onore di G.B. Pellegrini 2, Pisa: Parini, 1983, pp. 1023-1029

Note asupra utilizarii infinitivului in limbile romanice. - Analele societăţii de limba română 11/12, Zrenjanin 1983, pp. 195-196

\section{Artículos y contribuciones breves}

Anton Grad. - Naši razgledi 32, št. 7, Ljubljana 1983, pp. 202

\section{Reseñas, evaluaciones, informes}

Antonio Quilis. La concordancia gramatical en la lengua española bablada en Madrid, C.S.I.C.: Madrid 1983. - Linguistica 23, Ljubljana 1983, pp. 359-361

\section{4}

\section{Contribuciones científicas}

Italijanska etnija v Istri med bilingvizom in diglosijo. - V: Dvojezičnost - individualne in družbene razsežnosti. - Ljubljana: Društvo za uporabno jezikoslovje, 1984, pp. 287-293

I riflessi latini in sloveno. - V: Das Romanische in den Ostalpen, Österreichische Akademie der Wissenschaften. - Verlag der Österreichischen Akademie der Wissenschaften: Wien 1984, pp. 111-124

Elementi linguistici latini e romanzi nella lingua dei primi giornalisti sloveni. »Slovenski narod « 1868. - V: Est Europa 1, (Zbornik v čast sedemdesetletnice prof. Martina Jevnikarja), Udine: Università degli studi di Udine, 1984, pp. 57-66 


\section{Artículos}

Romanski jezikovni vplivi v tržaški knjižni slovenščini. Jezik Borisa Pahorja. - Linguistica 24, Ljubljana 1984, pp. 315-334

Bilinguismo e diglossia. - Scuola nostra 14, Rijeka 1984, pp. 45-52

\section{Artículos y contribuciones breves}

Nécrologies: Anton Grad. - Revue de linguistique romane 48, št. 189/190, Strasbourg 1984, pp. 265-266

\section{5}

\section{Contribuciones científicas}

Remarques sur la concordance des temps dans les langues romanes. - V: Zbornik u čast Petru Skoku. - Zagreb: JAZU, 1985, pp. 461-466

Subordinate volitive oggettive nell' antico italiano. - V: Actes de XVI. Congrés internacional de lingüística e filologia romàniques 2. - Palma de Mallorca: Moll, 1985, pp. 117-126

\section{Artículos}

Interferenze linguistiche sintattico-semantiche slavo-romanze sui territori limitrofi: la lingua di Alojz Rebula. - Incontri linguistici 10, Pisa 1987, pp. 89-103

\section{6}

\section{Contribuciones científicas}

Passato prossimo e passato remoto nei dialetti veneti. - V: Guida ai dialetti veneti 8. - Padova: CLEUP,1986, pp. 31-43

Caratteristiche morfosintattiche della parlata piranese. - V: G.I. Ascoli. Attualità del suo pensiero a 150 anni dalla nascita. Atti del XIII. Incontro culturale mitteleuropeo, Gorizia 1979. - Firenze: Licosa, 1986, pp. 159-162

La costruzione del periodo nella prosa italiana da Machiavelli a Galileo. - V: Actes congrès du XVII international de linguistique et pbilologie romanes 8. - Aix en Provence: Université de Provence, 1986, pp. 295-307 


\section{Artículos}

Interferenze linguistiche slavo-romanze: la lingua di Novi Matajur. - Linguistica 26, Ljubljana 1986, pp. 59-68

\section{Reseñas, evaluaciones, informes}

Linguistica XXV. - Naši razgledi, 35, št. 14, Ljubljana 1986, p. 415

\section{7}

\section{Contribuciones científicas}

Annotazioni ai nomi di famiglia in Istria, Romania et Slavia Adriatica. - V: Romania et Slavia Adriatica. Festscbrift für Žarko Muljačić. - Hamburg: H. Buske, 1987 , pp. $475-480$

\section{Artículos}

Romanske jezikovne prvine v jeziku slovenskih časopisov na Goriškem. - Die Slawischen Sprachen 11, Salzburg 1987, pp. 123-134

Petar Skok e gli inizi degli studi romanzi all' Università di Ljubljana. - Studi Goriziani 66, Gorizia 1987, pp. 87-92

\section{8}

\section{Libros y monografías}

Romanski jeziki. - Ljubljana: Filozofska fakulteta, Oddelek za romanske jezike in književnosti, 1988, XIII, 423 pp.

\section{Artículos}

Sintaktični vplivi romanskega sveta na zahodna slovenska narečja. - Filologija 16, Zagreb 1988, pp. 137-143

L'apporto linguistico sloveno al friulano di Gorizia. - Linguistica 28, Ljubljana 1988, pp. 55-66

Elementi non-italiani ed elementi non-romanzi nella parlata piranese. - Prace filologiczne 34, Warszawa 1988, pp. 397-401 


\section{Reseñas, evaluaciones, informes}

Ai margini di una pubblicazione importante: Mario Doria. Grande Dizionario del dialetto triestino. - Linguistica 28, Ljubljana 1988, pp. 133-139

Slovenska krajevna imena. Cankarjeva založba: Ljubljana 1985. - Linguistica 28, Ljubljana 1988, pp. 164-166

Jan Baudouin de Courtenay. Materiali per la dialettologia e l'etnografia slava meridionale, ZTT: Trst 1988. - Linguistica 28, Ljubljana 1988, pp. 167-169

\section{9}

\section{Libros y monografías}

Uvod v romansko jezikoslovje. 2. izd.. - Ljubljana: Filozofska fakulteta, Oddelek za romanske jezike in književnosti, 1989, 346 pp.

\section{Contribuciones científicas}

Skladenjska sovplivanja romanskega in slovanskega sveta na zahodni slovenski meji. - V: Jezici i kulture u doticajima: zbornik 1. medunarodnog skupa, Pula, 1415. IV 1988. - Pula: Pedagoški fakultet u Rijeci, 1989, pp. 255-259

\section{Artículos}

L'estructuració de l'oració composta en el Tirant lo Blanc. - Linguistica 29, Ljubljana 1989, pp.137-145

Janoš Hunyadi v katalonski epski književnosti. - Zgodovinski časopis 43, št. 3, Ljubljana 1989, pp. 411

Contributi all'onomastica istriana. - Scuola nostra 21, Rijeka 1989, pp. 137-142

\section{Artículos y contribuciones breves}

Oddelek za romanske jezike in književnosti/Miklič Tjaša. - V: Zbornik Filozofske fakultete v Ljubljani: 1919 - 1989. - Filozofska fakulteta: Ljubljana, 1989, pp. 173-187 


\section{0}

\section{Libros y monografías}

Uvod u romansku lingvistiku: udžbenik za predmet Istorija francuskog, španskog, italijanskog i rumunskog jezika, (Radovi Instituta za strane jezike i književnosti, D, Udžbenici i priručnici, 9). - Novi Sad: Institut za strane jezike i književnosti Filozofskog fakulteta, 1990, 302 pp.

\section{Contribuciones científicas}

L'italianistica e lo sviluppo degli studi d'italiano in Jugoslavia. - V: Lingua e cultura italiana in Europa. - Firenze: Le Monnier, 1990, pp. 431-437

\section{Artículos}

Skladenjski kalki romanskega izvora v zahodnih slovenskih govorih. - Razprave. Razred za filološke in literarne vede pri SAZU 2, št. 13, Ljubljana 1990, pp. $153^{-161}$

Una particolarità sintattica del piranese. - Lasa pur dir 7, Piran 1990, pp. 84-86

\section{Reseñas, evaluaciones, informes}

Lexikon der Romanistischen Linguistik ( $L R L)$. Édité par Günter Holtus - Michael Metzeltin - Christian Schmitt. Volume V, 1. Le français. Max Niemeyer Verlag, Tübingen 1988, XVI + 936. - Revue de linguistique romane 54, št. 215/216, 1990, pp. 539-549

Slovenski pravopis, I. Pravila. SAZU - Državna založba Slovenije: Ljubljana 1990. - Linguistica 30, Ljubljana 1990, pp. 231-232

Elena Rizzi, Italiano regionale e variazione sociale: L'italiano di Bologna. CLUEB: Bologna 1989. - Linguistica 30, Ljubljana 1990, pp. 233-234

Variatio Linguarum, Beiträge zu Spracbvergleich und Sprachentwicklung. Festschrift zum 6o. Geburtstag von Gustav Ineichen. Franz Steiner Ver.: Stuttgart 1989. - Linguistica 30, Ljubljana 1990, pp. 235-237

Studien zur romanistischen Wortgeschite. Festschrift für Heinrich Kuen zum 90. Geburtstag. Franz Steiner Ver.: Stuttgart 1989. - Linguistica 30, Ljubljana 1990, pp. 238-241

Svend Bach og. Jørgen Schmitt Jensen, Større italiensk grammatik. Munksgaards grammatikker: Munksgaard 1990. - Linguistica 30, Ljubljana 1990, pp. 242-244 
Grande grammatica italiana di consultazione. Vol. 1: La frase. I sintagmi nominali e preposizionali. Il Mulino: Bologna 1988. - Linguistica 30, Ljubljana 1990, pp. $245^{-254}$

\section{1}

\section{Contribuciones científicas}

Appunti sulla costruzione del periodo nella prosa contemporanea italiana. V: Actes du 18ème Congrès International de Linguistique et de Pbilologie Romanes 3. - Tübingen: Niemeyer, 1991, pp. 273-281

Interferenze linguistiche tra mondo slavo e romanzo con particolare riferimento ai territori limitrofi. - Itinerari di idee, uomini e cose fra Est ed Ovest europeo. - Aviano: Tricesimo, 1991, pp. 313-318

\section{Artículos}

Interferenze sintattiche di origine romanza nelle parlate slovene occidentali: la strutturazione del sintagma aggettivale, della frase, del periodo. - Linguistica 31, Ljubljana 1991, pp. 361-365

Romanstvo in slovenstvo na Goriškem: medsebojna jezikovna sovplivanja. Primorska srečanja, 16, št. 116, Nova Gorica 1991, pp. 171-174

\section{Artículos y contribuciones breves}

Vida Šturmova - osemdesetletnica. - Delo 33, št.110, Ljubljana 1991, p.7

\section{2}

\section{Contribuciones científicas}

Riflessi della poesia epica francese medievale nei nomi di persona romanzi di origine germanica. - V: Literature, Culture and Ethnicity. A Festschrift for Janez Stanonik. -Ljubljana: Filozofska fakulteta, 1992, pp. 277-282

\section{Artículos}

Un calco cervantino: Dios es grande. - Verba Hispanica 2, Ljubljana 1992, pp. 105-106 
Noms de persona en el Tirant lo Blanc. - Verba Hispanica 2, Ljubljana 1992, pp. 107-109

\section{Artículos y contribuciones breves}

Linguistica. - V: Enciklopedija Slovenije 6. - Ljubljana: Mladinska knjiga, 1992, p. 188

\section{Reseñas, evaluaciones, informes}

Lexikon der Romanistiscben Linguistik (LRL). Édité par Günter Holtus - Michael Metzeltin - Christian Schmitt. Volume IV, 1. Italiano, Corso, Sardo. Max Niemeyer Verlag, Tübingen 1990, XXII + 894. - Revue de linguistique romane 56 , št. $221 / 222,1992$, pp. 190-200

\section{3}

\section{Contribuciones científicas}

Calchi sintattici di provenienza friulana in sloveno. - V: Verbum Romanicum: Festscbrift für Maria Iliescu. - Hamburg: H. Buske, 1993, pp. 161-164

\section{Artículos}

Una metáfora cervantina: el norte de la caballería andante. - Verba Hispanica 3, Ljubljana 1993, pp. 119-121

\section{Reseñas, evaluaciones, informes}

Novejša dela iz italijanskega jezikoslovja. - Vestnik 27, 1/2, Ljubljana 1993, pp. 354-36o.

Lexikon der romanistischen Linguistik (LRL), VI, 1: Aragonés/Navarro, Español, Asturiano/Leonés). - Verba Hispanica 3, Ljubljana 1993, pp. 145-160

\section{4}

\section{Artículos}

Estructuración del período en el Quijote. - Verba Hispanica 4, Ljubljana 1994, pp. $187-190$ 


\section{Artículos y contribuciones breves}

Fran Šturm - a cinquant'anni dalla scomparsa. - Linguistica 34/2, Ljubljana 1994, pp. 1-2

\section{Reseñas, evaluaciones, informes}

Priromala v pristan ne bova skupaj: razsute pesmi. - Delo 36, št. 196, Ljubljana 1994, p. 14

Jože Toporišič, Enciklopedija slovenskega jezika. Cankarjeva založba: Ljubljana 1992. - Linguistica 34/2, Ljubljana 1994, pp. 152-153

Giovan Battista Pellegrini, La genesi del retoromanzo (o ladino). Beihefte zur Zeitschrift für romanische Philologie, Band 238. Max Niemeyer Verlag: Tübingen 1991. - Linguistica 34/2, Ljubljana 1994, pp. 154-156

\section{5}

\section{Contribuciones científicas}

L'italià i l'eslovè a Trieste en clau sociolingüistica. - V: Estudis de lingüística $i$ filologia oferts a Antoni M. Badia i Margarit. - Barcelona: Publicacions de l'Abadia de Montserrat, 1995, pp. 351-359

Interferenze linguistiche nella toponomastica dei territori plurietnici della regione Friuli-Venezia Giulia. V: Munus amicitiae: studia linguistica in honorem Witoldi Mańczak septuagenarii. - Cracoviae: Universitas Iagellonica, 1995, pp. 179-183

Calchi semantici di provenienza romanza nello sloveno occidentale. V: Scritti di linguistica e dialettologia in onore di Giuseppe Francescato. - Trieste: Ricerche, 1995, pp. 291-294

Prisotnost hispanistike v slovenski kulturi. - V: Informativni kulturološki zbornik. - Ljubljana: Seminar slovenskega jezika, literature in kulture pri Oddelku za slovanske jezike in književnosti Filozofske fakultete, 1995, pp. 309-317

\section{Artículos}

Krivenčenje latinskih besed v nekaterih romanskih književnih delih. - Živa antika 45, št.1/2, Skopje 1995, pp. 343-350

Metáfora sinestésica en El Quijote. - Verba Hispanica 5, Ljubljana 1995, pp. 89-92 


\section{Reseñas, evaluaciones, informes}

Gianfranco Folena, Vocabulario del veneziano di Carlo Goldoni. Istituto di Enciclopedia italiana: Venezia 1993. - Linguistica 35/2, Ljubljana 1995, pp. 335-337 Roberto Dapit, La Slavia friulana. Lingue e culture: Resia, Torre, Natisone. Bibliografia ragionata. Kulturno društvo"Ivan Trinko": Špeter. - Linguistica 35/2, Ljubljana 1995, pp. 338-340

Arnulf Stefenelli, Das Scbicksal des lateinischen Wortschatzes in den romanischen Sprachen, Passau 1992. - Linguistica 35/2, Ljubljana 1995, pp. 341-343

\section{Editor}

Mednarodni simpozij „Prototipičnost besedilnih vrst“, Ljubljana, 16.-18. novembra 1994. Besedilne vrste $=$ Textsorten.- Linguistica 35/1, Ljubljana: Filozofska fakulteta, 1995, $274 \mathrm{pp}$.

\section{6}

\section{Libros y monografías}

Uvod v romansko jezikoslovje. 3. izd. Ljubljana: Filozofska fakulteta, Oddelek za romanske jezike in književnosti, 1996. IV, 346 pp.

\section{Contribuciones científicas}

Kopitar in romanski jeziki. - V: Kopitarjev zbornik: mednarodni simpozij v Ljubljani, 29. junij do 1. julij 1994: simpozij ob stopetdesetletnici njegove smrti. - Ljubljana: Filozofska fakulteta, Oddelek za slovanske jezike in književnosti, Seminar slovenskega jezika, literature in kulture, 1996, pp. 321-326

\section{Artículos}

Zahodni slovenski govori: sociolingvistični pogledi. - Razprave. Razred za filološke in literarne vede pri SAZU 2, št. 15, Ljubljana 1996, pp. 79-86

Sancho, prevaricador del buen lenguaje. - Verba Hispanica 6, Ljubljana 1996, pp. $113-116$

\section{Reseñas, evaluaciones, informes}

Romanske jezikovne prvine v slovenskih zahodnih narečjih: zaključno poročilo o rezultatih opravljenega znanstveno-raziskovalnega dela na področju temeljnega raziskovanja. Ljubljana: Znanstveni inštitut FF, 1996, 4 pp. 


\section{7}

\section{Libros y monografías}

Romanske jezikovne prvine na zabodni slovenski jezikovni meji. - Ljubljana: Znanstveni inštitut Filozofske fakultete, 1997, 227 pp.

\section{Contribuciones científicas}

Italien-slovène. - V: Kontaktlinguistik. Halbband 2. - Berlin, New York: Walter de Gruyter, 1997, pp. 1357-1362

\section{Artículos}

Calchi di provenienza romanza nello sloveno occidentale. - Linguistica 37, Ljubljana 1997, pp. 99-106

\section{Reseñas, evaluaciones, informes}

Enzo Croatto, Vocabolario ampezzano. Cortina d'Ampezzo 1986. - Linguistica 37, Ljubljana 1997, pp. 140-141

Pierre Swiggers, Histoire de la pensée linguistique. Analyse du langage et réflexion linguistique dans la culture occidentale, de l'Antiquité au XIXème siecle. Presses universitaires de France: Paris 1997. - Linguistica 37, Ljubljana 1997, pp. 142-145

Beiträge zur rumänische Sprache im 19. Jabrbundert, Akten des Kolloquiums, Regensburg 26.- 28. April 1990. Max Niemeyer Verlag: Tübingen 1992. - Linguistica 37, Ljubljana 1997, pp. 146-148

\section{8}

\section{Contribuciones científicas}

Alle porte orientali d'Italia: incontro linguistico e sociolinguistico tra il mondo slavo e romanzo. - V: Atti del XXI Congresso internazionale di linguistica e filologia romanza. -Tübingen: Niemeyer:, 1998, pp. 571-577

\section{Reseñas, evaluaciones, informes}

Predmetni izpitni katalog za maturo. 2000, Italijanski jezik. - Ljubljana: Državni izpitni center, 1998, $58 \mathrm{pp}$. 
Un importante contributo alla lessicografia italo-slovena: Sergij Šlenc, Véliki italijansko-slovenski slovar - Il grande dizionario italiano-sloveno. Državna založba Slovenije: Ljubljana 1997. - Linguistica 38/2, Ljubljana 1998, pp. 203-208

1999

Artículos

Si a ti te mantearon una vez.... - Verba Hispanica 8, Ljubljana 1999, pp. 159-164

\section{Artículos y contribuciones breves}

Škerlj, Stanko. - V: Enciklopedija Slovenije 13, Ljubljana: Mladinska knjiga, 1999, p. 45

Šturm, Franc. - V: Enciklopedija Slovenije 13, Ljubljana: Mladinska knjiga, 1999, pp. $157^{-158}$

\section{Reseñas, evaluaciones, informes}

Willy Bal, Jean Germain, Jean Klein, Pierre Swiggers, Bibliograpbie sélective de linguistique française et romane. Duculot: Louvain-la-Neuve. Linguistica 39, Ljubljana 1999, pp. 153-155

\section{0}

\section{Libros y monografías}

Elementi linguistici romanzi nello sloveno occidentale. - Roma: Calamo, 2000, 230 pp.

\section{Artículos}

Perfecto presente en la obra literaria de Gabriel García Márquez. - Razprave. Razred za filološke in literarne vede pri SAZU 2, št. 17, Ljubljana 2000, pp. 163-172

\section{Reseñas, evaluaciones, informes}

Ladinia linguistica in una monumentale opera: Atlante linguistico del ladino dolomitico e dei dialetti limitrofi - ALD-1, Dr. Ludwig Reichert Verlag: Wiesbaden 1998. - Linguistica 40/1, Ljubljana 2000, pp. 188-195 


\section{1}

\section{Contribuciones científicas}

Veneto, friulano, sloveno: interferenze sintattiche. - V: Studi linguistici alpini in onore di Giovan Battista Pellegrini. Firenze: Istituto di studi per 1'Alto Adige, 2001, pp. [79]-88.

\section{Artículos}

Romansko-slovanske jezikovne interference: sosledica časov. - Slavistična revija 49, št. 4, Ljubljana 2001, pp. [229]-236

Una insula que hasta agora la espero. - Verba Hispanica 9, Ljubljana 2001, pp. $213-217$

\section{Reseñas, evaluaciones, informes}

Pavle Merkù, Slovenska krajevna imena v Italiji: manuale. Mladika: Trst 1999. Linguistica 41, Ljubljana 2001, pp. 178-180

Dieter Messner, Los manuales de español impresos en Viena en el siglo XVII: edición facsimil y comentario, vol. I-II, Institut für Romanistik der Universität Salzburg, Biblioteca hispano-lusa, Salzburg 2000, (pp. LX+856). - Verba Hispanica 9, Ljubljana 2001, pp. 239-240

André Thibault, Perfecto simple y perfecto compuesto en español preclásico: estudio de los perfectos de indicativo en "La Celestina", el "Teatro" de Encina y el "Diálogo de la lengua”, Beihefte zur ZRPh, Band 301, Max Niemeyer Verlag, Tübingen 2000, (XIV+240). - Verba Hispanica 9, Ljubljana 2001, pp. 241-243

\section{2}

\section{Libros y monografías}

Romanski jeziki. 2. predelana izd.. - Ljubljana: Filozofska fakulteta, Oddelek za romanske jezike in književnosti, 2002, XII + 345 pp.

\section{Contribuciones científicas}

L' area linguistica romanza e slava a contatto: influenze sintattiche. - V: Scritti offerti a Mario Doria in occasione del suo 80 compleanno. - Trieste: Università degli Studi, 2002, pp. 168-174 
Calques syntaxiques slavo-romans. - V: Roma et Romania: Festschrift für Gerbard Ernst zum 65. Geburtstag. - Tübingen: Niemeyer, 2002, pp. 351-358

\section{Artículos}

España en el periódico Slovenski narod 1868. - Verba Hispanica 10, Ljubljana 2002 , pp. $125^{-146}$

\section{3}

\section{Artículos}

Otro dia - a doua zi. - V: Studi in memoria di Eugenio Coseriu. Supplemento a Plurilinguismo. - Udine: Centro Internazionale sul Plurilinguismo, 2003, pp. 397-404

Il pronome relativo che in friulano. - Linguistica 43, Ljubljana 2003, pp. 65-72 Otro día había de volver al duro ejercicio de las armas. - Verba Hispanica 11, Ljubljana 2003, pp. 87-91

\section{Reseñas, evaluaciones, informes}

Goran Filipi, Istrorumunjski lingvistički atlas. Atlasul lingvistic istroromân. Atlante linguistico istrorumeno, Knjižnica Atlas, Knjiga 2, Znanstvena udruga Mediteran=Societas studiorum Mediterraneum: Pula 2002. - Linguistica 43, Ljubljana 2003, pp. 161-163

Žarko Muljačić, Das Dalmatiscbe Studien zu einer Untergegangenen Spracbe. Quellen und Beträge zur croatischen Kulturgeschichte 10. Böhlau Verlag: Köln, Weimar, Wien 2000. - Linguistica 43, Ljubljana 2003, pp. 164-167

\section{4}

\section{Artículos}

Prevzete besede in kalki na zahodnem slovenskem jezikovnem območju. Annales: Anali za istrske in mediteranske študije. Series Historia et Sociologia 14, št. 2, Koper 2004, pp. 315-322

El perfectum praesens en català. - Verba Hispanica 12, Ljubljana 2004, pp. $155^{-158}$ 


\section{Reseñas, evaluaciones, informes}

Maurizio Puntin, Toponomastica storica del territorio di Monfalcone e del comune moderno di Sagrado, Centro Isontino di Ricerca e Documentazione storica e sociale „Leopoldo Gasparini“, Gradisca d'Isonzo - SKRD Jadro, Ronchi dei Legionari - SKŠRD Tržič: Monfalcone 2003. - Linguistica 44, Ljubljana 2004, pp. 161-166

Géograpbie linguistique et biologie du langage: autour de Jules Gilliéron. Orbis supplementa 20. Peeters Leuven: Leuven - Paris - Dudley, MA 2002. Linguistica 44, Ljubljana 2004, pp. 167-171

Il Registro della confraternita dei pellicciai di Udine. Biblioteca di Lingua e Letteratura friulana 4. Forum, Editrice Universitaria Udinese: Udine 2003. - Linguistica 44, Ljubljana 2004, pp. 190-192

Anna Genco, Gli elementi sloveni nei dialetti italiani settentrionali; tesi di laurea. Facoltà di Magistero dell'Università di Padova, 1957/58. - Plurilinguismo. Conttati di lingue e culture 11, Udine 2004, pp. 264-266

\section{5}

\section{Artículos}

Il dativo etico nel friulano sonziaco. - Linguistica 45, Ljubljana 2005, pp. 283-288

\section{Artículos y contribuciones breves}

Leksikalni vplivi slovenskih zahodnih narečij na obsoško furlanščino. - Glas. ZRS, Koper 2005, let. 10, št. 3, pp. 27

\section{6}

\section{Libros y monografías}

Slovenske jezikovne prvine v obsoški furlanščini. - Ljubljana: Znanstvenoraziskovalni inštitut Filozofske fakultete, 2006, 152 pp.

\section{Contribuciones científicas}

Un valor particular del verbo en el Quijote: perfecto presente. - V: Interpretaciones del Quijote: slovenski prispevek ob 40o. obletnici izida. - Ljubljana: Znanstvenoraziskovalni inštitut Filozofske fakultete, 2006, pp. 227-235 
Lingue in contatto: elementi lessicali sloveni nel friulano sonziaco. - V: Studi linguistici in onore di Roberto Gusmani. - Alessandria: Edizioni dell'Orso, 2006, pp. [1642]-1650

\section{Artículos}

Leksikalni vplivi slovenskih zahodnih govorov na obsoško furlanščino. - Annales: Anali za istrske in mediteranske študije. Series Historia et Sociologia 16, št. 1, Koper 2006, pp. 155-160

Mi oíslo. - Verba Hispanica 14, Ljubljana 2006, pp. 189-191

El lingüista esloveno Bartolomé Kopitar y el iberorromance. - Verba Hispanica 14, Ljubljana 2006, pp. 193-195

\section{7}

\section{Libros y monografías}

Uvod v romansko jezikoslovje. 4. predelana izd.. - Ljubljana: Filozofska fakulteta Univerze, Oddelek za romanske jezike in književnosti, 2007, 205 pp.

\section{Contribuciones científicas}

Slovenske leksikalne prvine v obsoški furlanščini: izpeljanke. - V: Jezikoslovni zapiski [Merkujev zbornik]. - Ljubljana: Založba ZRC, 2007, pp. 345-350

\section{Artículos}

Jezika v stiku: slovenščina in furlanščina. Prevzete besede in kalki. - Slavistična revija 55, št 1-2, Ljubljana 2007, pp. [19]-29

Elementi lessicali Sloveni nell'antico Friulano sonziaco. - Razprave. Razred za filološke in literarne vede pri SAZU 2, št. 20, Ljubljana 2007, pp. 237-249

El escritor esloveno Francè Bevk y su viaje en España en 1935. - Verba Hispanica 15/b, Ljubljana 2007, pp. 167-169

\section{Artículos y contribuciones breves}

Pavao Tekavčić: 1931-2007. - Bollettin della SLI 25, št. 1, Roma 2007, pp. 35-37

Pavao Tekavčić: 1931-2007. - Linguistica 2007, letn. 47, pp. 3-4 


\section{Reseñas, evaluaciones, informes}

Un importante contributo alla lessicografia italo-slovena: Sergij Šlenc, Veliki slovensko-italijanski slovar-Il grande dizionario sloveno-italiano, Državna založba Slovenije, Ljubljana, 2006; pp. XIV + 1539. - Linguistica 2007, št. 47, pp. 159-165

Mons. Ivan Trinko (1863-1954). Spodbujevalec spoznavanja in dialoga med kulturami/Promotore della conoscenza e del dialogo tra le culture. Kulturno društvo/ Circolo culturale I. Trinko, Čedad/Cividale 2006. - Linguistica 2007, št. 47, pp. $165-166$

Rada Cossutta - Franco Crevatin, Slovenski dialektološki leksikalni atlas slovenske Istre (SDLA-SI) II, Založba Annales 2006. - Linguistica 2007, št. 47, pp. 166-167

\section{8}

\section{Artículos}

La venta que él se imaginaba ser castillo. - Verba Hispanica 16, Ljubljana 2008, pp. $107^{-115}$

La guerra civil en España y la escisión en la esfera católica eslovena: Edvard Kocbek . - Verba Hispanica 16, Ljubljana 2008, pp.141-145

\section{9}

\section{Artículos}

El campo semántico del parentesco primario en El Quijote. - Verba Hispanica 17, Ljubljana 2009, pp. 139-144

\section{Reseñas, evaluaciones, informes}

Rada Cossutta - Franco Crevatin: Slovenski dialektološki leksikalni atlas slovenske Istre (SDLA-SI), II, Založba Annales, Koper 2006. - Vestnik za tuje jezike 2009, letn. 1, št. 1/2, pp. 221-224 


\section{0}

\section{Libros y monografías}

Romanistika na Slovenskem. 1. Izd. . - Ljubljana: Znanstvena založba Filozofske fakultete, 2010, $103 \mathrm{pp}$.

\section{1 \\ Artículos \\ "De cuyo nombre no quiero acordarme". Verba Hispanica 19, Ljubljana 2010, pp. $143-148$}

\section{3}

\section{Artículos}

Tempora si fuerint nubila. Verba Hispanica 21. - 2013, pp. 117-128

Tendenza al minor sforzo dell'espressione nelle lingue romanze. Linguistica 53 , št. 1, pp. 9-16

\section{4}

\section{Artículos}

Dragocen prispevek k poznavanju kontrastivnosti med romanskim in slovanskim jezikovnim svetom. Vestnik za tuje jezike 2014, letn. 6, št. 1, pp. 253-259

\section{Reseñas, evaluaciones, informes}

Markič, Jasmina e Nunes Correia, Clara (eds.) (2013): Descrições e contrastes. Tópicos de gramática portuguesa com exemplos contrastivos eslovenos. Ljubljana: Znanstvena založba Filozofske fakultete. pp. 152, Verba Hispanica 22, pp. 219-227 